\title{
Reasons for Belief, Reasons for Action, the Aim of Belief, and the Aim of Action* $^{*}$
}

\author{
Daniel Whiting
}

This is a post-peer review version of the paper posted online in 2013. The paper is to appear in Epistemic Norms, edited by Clayton Littlejohn and John Turri (Oxford: Oxford University Press, forthcoming). Please refer to the published version.

\section{$1 \quad$ Introduction}

Subjects take something to provide reason for believing that $p$ only if it seems to provide evidence that $p$. If evidentialism is the thesis that only evidence provides reason for believing, then subjects are committed to evidentialism. ${ }^{1}$ To say this is, of course, to say that subjects cannot take practical considerations - the kind which might favour or justify an action or decision — to favour or justify believing.

To bring this down to earth, consider the following. Barton's play recently opened on Broadway. Barton knows that it would make him happy to believe that the critics loved the play. But Barton cannot take this non-evidential consideration to justify believing that the critics loved the play, in the way that he might take the fact that it would make him happy to do so to justify reading the critics' favourable reviews. In contrast, suppose that Barton has just read a number of glowing reviews. Presumably, he could take the evidence this provides to justify believing that the critics loved the play.

\footnotetext{
* Thanks to Sophie Edwards, Daniel Greco, Conor McHugh, Ema Sullivan-Bissett, Jonathan Way, and audiences at Southampton and St Louis for comments.

${ }^{1}$ There are other conceptions of evidentialism to be found in the literature. Sometimes evidentialism is presented as a normative thesis, according to which one should not believe that $p$ unless one has evidence that $p$ (cf. Feldman 2000). This follows straightforwardly from evidentialism as construed here.
} 
Many would accept that subjects are committed to evidentialism in something like the way outlined above-indeed, the view is close to orthodoxy. Of course, nothing in philosophy is uncontroversial and there are those who would reject it. It is not my aim here to defend the claim but to take it for granted and consider what might explain it.

That subjects do not take practical considerations to justify belief appears puzzling; after all, many of those considerations are apt to appear more pressing than matters of truth or falsity. Suppose that one knows that if one were to believe that David Cameron's doctor's uncle has 132,487 hairs on his head one would receive a generous amount of money. Whether or not the belief is true seems not to matter in the slightest or, at least, whatever importance it has seems outweighed by the prospect of money. Nonetheless, since the fact that one would receive a financial reward were one to have the relevant belief is no evidence that the belief is true, it seems one cannot take it to justify so believing. Why? ${ }^{2}$

This problem seems to be generated by something like the following picture. ${ }^{3}$ There are situations in which what one might call the epistemic perspective- - one's point of view qua believer — clashes with what one might call the practical perspective-one's point of view qua agent. One could capture this picture as follows:

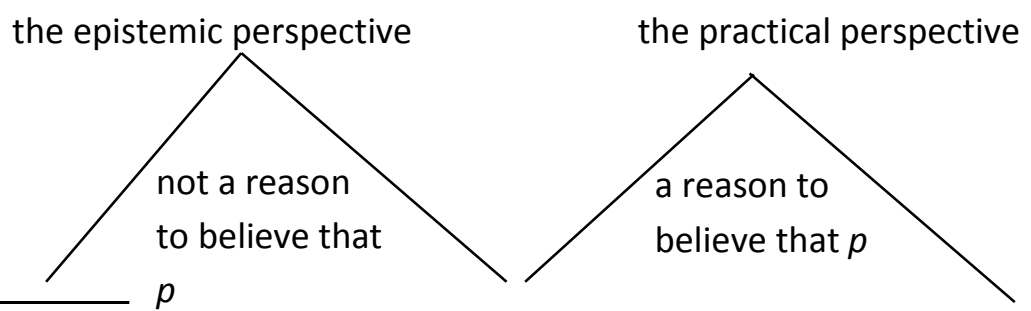

\footnotetext{
${ }^{2}$ One might think that the answer to this is that belief is a state, something one is in, not an action, something one does. Since practical considerations favour actions, it is no surprise that subjects do not take them to favour beliefs. Arguably, however, there can be practical reasons to be in a state - it is not obviously infelicitous, for example, to claim that there are reasons for being in London this weekend. Moreover, judgement, which typically issues in belief, is a (mental) action; but, as with belief, subjects do not take practical considerations to favour judging. Finally, on some views, belief is an action (cf. Boyle 2011). In any event, this answer to the puzzle is not widely accepted and so it is worth exploring an alternative.

${ }^{3}$ Compare: 'In cases in which what it is epistemically rational to believe clearly diverges from what it is practically advantageous to believe, there is simply no genuine question about what one should believe: Although we can ask what one should believe from the epistemic perspective and we can ask what one should believe from the practical perspective, there is no third question: what one should believe all things considered' (Kelly 2003: 619).
} 
Suppose that the evidence that my son is lying is overwhelming but believing that he is telling the truth would influence my dispositions toward him in such a way as to improve our relationship, which would in turn make him more likely to tell the truth in the future. From the epistemic perspective, I have no reason for believing that my son is telling the truth; from the practical perspective, one might think, I do. Why, then, am I unable to take the facts about the practical import of believing that my son is telling the truth to be reason for so believing? Why does the epistemic perspective eclipse the practical perspective?

In what follows, I shall sketch a novel answer to this problem, one which eventually involves rejecting the above picture. Along the way, in addition to the claim that subjects are committed to evidentialism, I shall make other somewhat controversial claims. Though I shall try to provide some motivation for and defence of those claims as appropriate, my main aim is to bring them together as a coherent story, one which seems worthy of further exploration and development.

\section{$2 \quad$ Truth and the aim of belief}

Suppose that belief has an aim. ${ }^{4}$ Some take such talk to concern how belief is causallyregulated at the sub-personal level. Though little in what follows hangs on this, since what calls for explanation on this occasion is the fact that subjects take only evidential considerations to provide reason for believing, I shall present the relevant aim as one possessed at the personal level (which is not to reject claims about goings-on at lower levels). That a subject aims to $\varphi$ has implications for how she is inclined or motivated to act, what

\footnotetext{
${ }^{4}$ I shall not attempt here to tackle head on objections to the very idea that belief has an aim, though what follows goes some way to responding to those who reject it on the grounds that attributing an aim to belief fails to explain why subjects take only evidential considerations to justify belief (cf. $\mathrm{n} 7$ ).
} 
reasons she takes there to be, and what considerations she responds to as such. If my aim is to ensure that the plant in my office prospers, I will be inclined to prune it regularly, motivated to feed it when I notice its leaves taking on a yellowish tint, and take the fact that its soil is dry to be a reason to water it.

Suppose that subjects aim to believe that $p$ only if it is true that $p .{ }^{5}$ Some explicitly argue or implicitly assume that, by appeal to this idea, one might explain why subjects are committed to evidentialism. ${ }^{6}$ A subject takes something to be a reason for believing that $p$ only if it provides evidence that $p$, because only evidence that $p$ indicates that, were she to believe that $p$, she would satisfy her aim to do so only if $p$. Suppose that Barton aims to believe only the truth. It would make Barton happy to believe that the critics loved his play but, of course, Barton cannot take this to be evidence that the critics loved his play, and so he cannot take it to indicate that, were he to believe that the critics loved his play, he would accord with his aim in doing so, namely, to believe only the truth; thus, he cannot take it to justify doing so.

However, subjects have many aims, including practical. Granting that there is an aim to believe only the truth, why should it dominate? Suppose that Barton aims to be happy. Though Barton knows that believing that the critics loved his play would contribute to the satisfaction of this aim, he cannot take it to justify so believing.

The appeal to belief's aim appears not to have solved but to have postponed the original problem. Why can't a subject take practical considerations to provide reason for

\footnotetext{
${ }^{5}$ This claim is widely endorsed (e.g. Littlejohn 2012; Millar 2004; Steglich-Petersen 2008; Velleman 2000; Williams 1973). For discussion, see Whiting 2012.

Some claim that a subject aims to believe that $p$ only if she knows that $p$ (e.g. Adler 2002; Bird 2007; McHugh 2011; Williamson 2000). This entails that a subject aims to believe only the truth and therefore is consistent with the story I tell here. For criticism, see Whiting Forthcoming.

${ }^{6}$ This is more or less explicit in Adler 2002; Millar 2004; Steglich-Petersen 2008; Velleman 2000.
} 
believing when those considerations indicate that so believing accords with or satisfies her practical aims? Why does the aim to believe only the truth silence a subject's practical aims? ${ }^{7}$

Returning to the above picture, it is plausible to think that the aim to believe only the truth determines the epistemic perspective. It is unsurprising, then, that appealing to that aim alone should not resolve the puzzle of why that perspective eclipses all others when a subject is faced with the question of what to believe, given that the question appears to be one which can also be asked from the competing practical perspective.

In response to concerns of this sort, the usual move is to appeal to the idea that the relevant aim is constitutive, in the sense that one's attitude would not be one of believing that $p$ unless it were governed by the aim of having that attitude only if $p .{ }^{8}$ Unfortunately, this move does not get us very far. Suppose that, if one is to count as playing chess, one must play with the aim of following its rules. It hardly follows from this that one cannot take there to be reasons to violate the rules of chess, let alone that one cannot view certain considerationssay, aesthetic or moral — which have nothing to do with those rules as bearing on the issue of whether to move a certain piece. Even if one decides to move one's rook horizontally, in making that decision one might take into account such facts as that to move it in this way would be elegant, or that one's novice opponent's feelings would be hurt if one's victory were too quick. So, returning to the case at hand, granting that aiming to believe only the truth is constitutive of believing, it remains to be explained why subjects do not take nonevidential considerations to provide reason for believing.

\footnotetext{
${ }^{7}$ Owens (2003) denies that belief has an aim on the grounds that, if it did, one would expect its aim to interact with other aims, including practical, and so one would expect evidential considerations not to dominate as they do (cf. Kelly 2003; Shah 2003). For a response to Owens, see Steglich-Petersen 2009. For criticism of SteglichPetersen, see McHugh 2012; Sullivan-Bissett and Noordhof 2013.

${ }^{8}$ Shah (2006) suggests that the fact that subjects accept a norm according to which one should believe that $p$ only if $p$ explains why they take only evidential considerations to provide reason for believing. While I accept that belief is governed by a truth-norm (cf. Whiting 2010), and while a full discussion of Shah's proposal is beyond the scope of this paper, I think it faces problems analogous to those I discuss here.
} 
To hammer the point home, consider the view that the constitutive aim of assertion is satisfied only if one asserts the truth (cf. Whiting 2013). Those who hold it would hardly deny that subjects take practical considerations to speak for or against asserting. One might take the fact that in doing so one would avoid offending one's audience as a reason for asserting a falsehood, even though in doing so one would violate the constitutive aim governing assertion. ${ }^{9}$

So, the problem remains. Given that we have practical as well as epistemic aims, why do the latter dominate when it comes to believing?

\section{$3 \quad$ Practical reasons and the aim of belief}

Here is a suggestion. The aim of belief is to provide only premises for practical and theoretical reasoning, that is, premises from which one might reason in deciding what to do and what to think. ${ }^{10}$ (For simplicity's sake, I shall focus on practical reasoning.) Though I shall provide some support for the suggestion, my aim is not to prove that it is correct but to consider its implications for the problem at hand. That said, the fact that, as I shall argue, the suggestion helps to explain an otherwise puzzling phenomenon provides additional support for it.

The conclusion of practical reasoning is an action or a decision (which in turn might result in an intention). The premises in a person's practical reasoning, and so which constitute the basis on which she acts or decides, are the contents of her beliefs. Of course, one can reason from certain assumptions but, unless one accepts those assumptions, the reasoning will

\footnotetext{
${ }^{9} \mathrm{McHugh}$ (Forthcoming), also appealing to the example of assertion, makes the related point that the fact that an act is constitutively subject to a norm does not preclude the possibility that certain considerations might motivate a subject to act in violation of it.

${ }^{10}$ I first floated, but did not develop, a version of this idea in Whiting 2010. Bird makes a similar suggestion when he says that, 'when engaged in practical deliberation whose outcome is an action, the function of belief is to supply inputs to that process' (2007: 94). In passing, Railton relates the thought that belief aims at truth to 'its distinctive role, alongside desire, in shaping action' (1994: 74). Finally, Littlejohn independently advances the view that 'what beliefs are supposed to do is represent how things are so that we might rely on them for the purpose of deliberation' (2012: 238). None of the above spell out or argue for the idea as I do here, and none bring it to bear on the issue at hand.
} 
not issue in an action or decision. ${ }^{11}$ Thus, there is an intimate link between what a person believes and what figures in her practical reasoning. This point relates in turn to the broadlyspeaking functionalist idea that, if one believes that $p$, one is disposed to act as if $p$ (in suitable circumstances). This all suggests that belief is the fundamental grounds for action. Perhaps it does not follow from these claims about the causal-dispositional role of belief vis-à-vis practical reasoning and its upshot that subjects aim to have beliefs which are fit to serve that role. That they do indeed have this aim shows up in the fact that, if a subject believes a certain proposition but comes to think that it is not one she can rely on in her practical reasoning, this will typically motivate her not to believe that proposition. Suppose that Holly believes that there is milk in the fridge but learns that that proposition is not one which could support or which otherwise bears on any decision she might face, such as whether to buy milk. One would expect Holly to be motivated not to use the proposition that there is milk in the fridge as a premise in any stretch of practical reasoning, and thereby to cease to believe it.

Moreover, it is plausible to think that the aim to believe only what is a practical reason is constitutive of believing. If a subject is indifferent as to whether the content of her attitude provides guidance for her actions and decisions, her attitude does not appear to be one of belief. Suppose that Holly holds some attitude toward the proposition that there is milk in the fridge. She is aware of some fact, say, that the fridge is empty, which shows that the proposition that there is milk in the fridge is not one she can rely on in practical reasoning and is not one which bears on whether to buy milk, but she is unmoved by that fact and does not take it to provide any reason to change her attitude. Whatever attitude it is that Holly has toward the proposition that there is milk in the fridge, it does not appear to be one of belief (as opposed to imagination, or hope, or...).

\footnotetext{
${ }^{11}$ Might one act on an assumption which one knows is false, so long as one believes that it approximates to the truth? Such a case is better described as one of acting on a belief that such-and-such is approximately true, or that so-and-so is approximately this-and-that.
} 
I shall do more to motivate and defend the attribution of this aim in the sections which follow. For now, grant that one's aim in believing that $p$ is satisfied only if that $p$ is a consideration which favours or justifies a practical conclusion, that is, a decision or action. Alternatively, one's aim in believing that $p$ is satisfied only if that $p$ is a practical reason. ${ }^{12}$ Consider the following. Hayley knows that believing that a new Wenders film is showing would make her happy. Hayley cannot take this fact to justify believing that a new Wenders film is showing, since it in no way indicates that, were she so to believe, she would satisfy or accord with her aim in doing so. That is, that it would make her happy to believe that a new Wenders film is showing does not indicate that what she would believe, were she so to believe, is a practical reason. Suppose that Hayley is deciding whether to go the cinema. She believes that a new Wenders film is showing. But that believing this makes her happy does not show that what she believes has any real consequences for the decision facing her. Alternatively, believing that a new Wenders film is showing on the grounds that it would make her happy to do so is not a way of pursuing the aim to believe only what is a practical reason. Given that aim, Hayley cannot take practical considerations to favour or justify believing.

In contrast, suppose that Hayley has read the current film-listings, according to which a new Wenders film is showing. This indicates that she would not conflict with the aim of believing only what is a practical reason if she were to believe that a new Wenders film is showing. If Hayley forms this belief, that the film-listings state that a new Wenders film is showing indicates that what she believes has real consequences for deciding whether to go to the cinema. Given the aim to believe only what is a practical reason, it is no surprise that Hayley would take an evidential consideration to justify believing.

\footnotetext{
${ }^{12}$ A variant would be that one's aim in believing that $p$ is satisfied only if that $p$ is practically relevant, where something might be practically relevant other than by being a practical reason, say, by being an enabling condition for a practical reason. For simplicity's sake, since nothing in what follows hangs on this, I shall stick to the specification of belief's aim given above.
} 
Stated more generally, the proposal is as follows. A subject takes something to be a reason for believing that $p$ only if it provides evidence that $p$, because only evidence that $p$ indicates that, were she to believe that $p$, she would satisfy her aim to believe that $p$ only if that $p$ is a practical reason.

In effect, I am suggesting that the aim of believing only what is a practical reason generates or incorporates a more familiar aim which is satisfied only if one's belief is true, that is, only if what one believes is a fact. Hayley believes that a new Wenders film is showing. What she believes hardly supports or justifies going to the cinema if what she believes is false (though, of course, it might appear to do so). Admittedly, this assumes that practical reasons are facts or truths, defending which is beyond the scope of this paper. For present purposes, note only that the view is relatively uncontroversial and motivated independently of any debates over belief's aim, the truth of evidentialism, or what might explain our commitment to it. ${ }^{13}$

Given that the aim to believe only what is a practical reason generates an aim to believe only what is true, one might complain that introducing the former adds nothing new. However, appealing to the independently motivated suggestion that subjects aim to believe only what is a practical reason explains why they aim to believe only the truth - subjects have the former aim because they have the latter aim. Moreover, as I shall argue below, focusing on the aim to believe only what is a practical reason helps to explain subjects' commitment to evidentialism in a way that focusing on the aim to believe only the truth does not.

\section{The aim of action}

\footnotetext{
${ }^{13}$ I also assume that facts are truths, an assumption not shared by all those who think that practical reasons are facts (cp. Dancy 2000). But nothing in what follows depends on this. If what one believes when one believes a truth is not a fact, and so not a practical reason, it corresponds to a fact, and so a practical reason. So, one might say, the aim to believe only the truth is a consequence of the aim to believe only what corresponds to a practical reason.
} 
One might think that, granting that subjects aim to believe only what is a practical reason, the same old issues reappear, albeit dressed in new clothes. Suppose that Barton aims to believe only what could justify or favour a practical conclusion. Still, he also aims to be happy. Why, then, doesn't Barton take the fact that believing that the critics loved his play would make him happy to justify so believing? Why does the aim to believe only what is a practical reason dominate?

To make progress, consider the issue of why the aim of belief is to provide only practical reasons. That aim, I suggest, is a consequence of the aim of (intentional) action. It is plausible to think that, as an agent, one aims to be guided in one's practical reasoning only by the facts, and so to act and decide only on the basis of practical reasons. That subjects do have this aim shows up in the fact that, if a subject takes a certain consideration not to be a reason to $\varphi$, either because that consideration does not bear on $\varphi$ ing or because it does not actually obtain, then that consideration will not motivate her to $\varphi$ or figure in her deliberation with respect to $\varphi$ ing. One would not expect the thought that a new Wenders film is showing to motivate Hayley to go the cinema this evening, or to figure in her reasoning as to whether to do so, if she takes it to be false or to be an illegitimate consideration (say, because the cinema is closed this evening).

It is as plausible that the aim to act only on the basis of practical reasons is constitutive of agency. A subject who does not in some sense aim to be guided only by practical reasons, that is, who is indifferent as to whether the considerations which lead her to do something really justify or favour doing that thing, simply does not seem to be engaged in practical reasoning.

Suppose that Harry shakes his head in response to entertaining a certain consideration, namely, that he has been asked if he needs a drink. Harry does not aim, in shaking his head, to do so only on the basis of practical reasons - he has no aims at all with respect to head- 
shaking. So, even though Harry takes the relevant consideration not to obtain- - he knows that he has not really been asked if he needs a drink — and so takes it not really to be a reason for shaking his head, this in no way moves him; it does not motivate him not to shake his head or even lessen his inclination to do so. Harry is indifferent as to whether the consideration which prompts his head-shaking is really a practical reason, that is, a fact which might favour or justify his doing so. Harry appears not to be acting (in the relevant sense) and whatever process leads him from the consideration that he has been asked if he needs a drink to shaking his head seems not to be one of practical reasoning.

The above remarks do not prove that subjects constitutively aim to be guided in acting and deciding only by practical reasons. The intention is only to show that there is something to this thought, and to consider how it might bear on the issue at hand.

Grant, then, that a subject aims to act (and decide) on the basis that $p$ only if that $p$ is a practical reason. ${ }^{14}$ Given the assumption that, when one acts, one acts on one's beliefs, this aim generates or incorporates the aim to believe only what is a practical reason, which in turn generates or incorporates the aim to believe only what is true.

With this in view, it begins to make sense why the aim to believe only what is a practical reason, and so to believe only the truth, dominates particular practical aims. It is because the aim of belief is dictated by practical reason itself; that is, the aim of belief is a subsidiary of the aim of practical reasoning, which is constitutive of agency. Alternatively, the aim to act only on practical reasons constitutively governs action, and so any particular practical aim one has must accord with this more general aim and any other aims that result from it, including the aim to believe only the truth. Thus, a subject cannot have a particular practical aim which conflicts with and overrides the aim to believe only the truth.

\footnotetext{
${ }^{14}$ A variant would be to suggest that one aims to act only in light of practically relevant considerations (cf. n12).
} 
Recall the picture presented above, according to which the epistemic perspective can clash with the practical perspective. On the view sketched here, this picture is mistaken. The epistemic perspective — which is determined by the aim to believe only truths — is contained within and dictated by the practical perspective — which is determined by the aim to act and decide on the basis of only practical reasons. Thus, apparent clashes between the perspectives are just that: apparent. In aiming to believe only what is true, one aims to believe only what might support or justify an action or decision, and so one aims to accord with the aim of action or practical reasoning. Alternatively, in aiming to believe only what is true, one aims to have only beliefs on the basis of which one might act in a way that accords with the aim constitutive of agency.

There is, then, an incoherence in the thought which underlies the puzzle. It assumes that, from the practical perspective, a subject might take there to be practical considerations which favour believing. But, if the above is along the right lines, such a subject would precisely not be adopting the practical perspective; it is in viewing those considerations from the practical perspective that she cannot take them to favour believing. One might capture this alternative way of looking at things as follows:

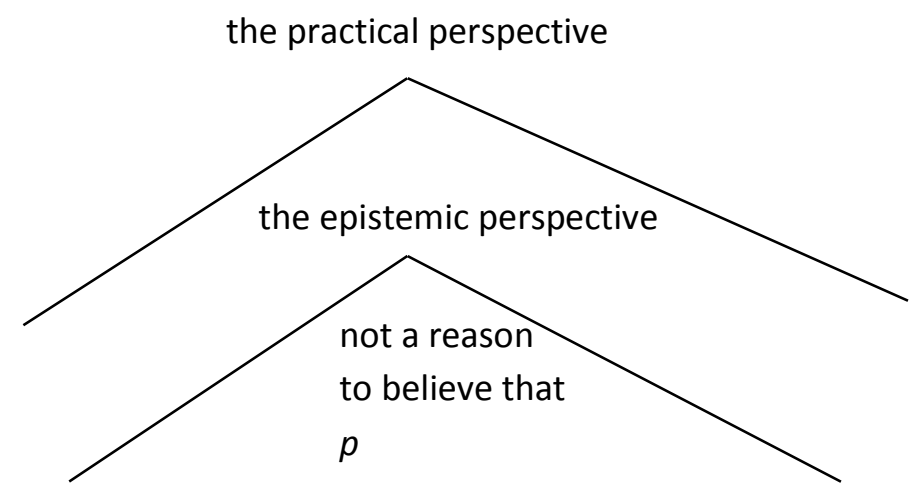

that it would be beneficial to believe that $p$ 
So, perhaps surprisingly, evidentialism is a commitment subjects have, not only as believers, but as agents. What explains the fact that subjects take only evidential considerations to provide reason for believing is the aim to act and decide only on practical reasons, which in turn generates an aim to believe only what is a practical reason. A subject takes something to be a reason for believing that $p$ only if it provides evidence that $p$, because only evidence that $p$ indicates that, were she to believe that $p$, she would have a basis on which to act in a way which accords with her aim to act on only what is a practical reason.

Initially, I suggested that the appeal to belief's aim does not provide a satisfactory solution to the problem at hand, since it is not clear why belief's aim should dominate over practical aims when the two are at odds. But we can now see that this problem arises only from a misconception of how those two aims relate. Belief's aim is not at odds with the aim of practical reason — and so does not dominate it—but rather is determined by it.

\section{$5 \quad$ Objections and replies}

\subsection{How does the aim of action generate the aim of belief?}

One might object to the above explanation of the fact that subjects do not take practical considerations to provide reason for believing on the following grounds. The account is too quick to suggest that, if a subject aims to act only on practical reasons, that is, only on facts, then she aims as a result to believe only what is a practical reason, that is, only what is true. At the very least, it requires the assumption that the relevant subject appreciates the role that belief plays in practical reasoning; otherwise, she might have the relevant aim in acting but fail to form the relevant aim in believing.

If the account does require the above assumption, that would not be a problem—grasp of the role belief plays in guiding action seems to come with the very concept of belief. Recall that I am trying to explain the fact that subjects take only evidential considerations to 
provide reason for belief. If having this commitment to evidentialism requires having the concept of belief, and if having the concept of belief involves appreciating that one acts and decides on the basis of what one believes, then the relevant assumption is, so to speak, given with that which is to be explained.

However, whether this assumption is indeed needed depends on whether one reads the relevant claims about aims as de dicto or de re ${ }^{15}$ The claim that a subject aims to drink water might be read de dicto as the claim that she has an aim with a content in which the notions of drinking and water figure. Thus, if a subject aims to drink water, read de dicto, it does not follow that she aims to consume $\mathrm{H}_{2} \mathrm{O}$, also read de dicto; after all, she might lack the concept of $\mathrm{H}_{2} \mathrm{O}$. Alternatively, the relevant claim might be read de re as the claim that a subject aims, with respect to drinking water, to do that, which does not entail that she has the concepts of drinking or water. Thus, if a subject aims to drink water, read de re, she thereby aims to consume $\mathrm{H}_{2} \mathrm{O}$, also read de re.

Returning in light of this to the case at hand, if the aim to act only on practical reasons, read de dicto, is to generate an aim to believe only what is true, also read de dicto, then the subject whose aim it is must possess the concept of belief and so grasp the role of belief in guiding action. But, if the aim to act only on practical reasons, read de re, generates an aim to believe only truths, also read de re, then a subject need not do so; indeed, to have the former aim, so understood, is thereby to have the latter aim.

So, it is not clear that the suggestion that the aim to act on the basis that $p$ only if that $p$ is a practical reason generates an aim to believe that $p$ only if $p$ requires the assumption that subjects appreciate the fact that what one acts on is what one believes; and, if it does require this, it is not clear that this is a problem.

\footnotetext{
${ }^{15}$ For discussion of the distinction between desire de dicto and desire de re, see Smith 1994.
} 


\subsection{Does the account assume a controversial view of the aim of action?}

One might object to the account on the grounds that it assumes a controversial view of the constitutive aim of action or practical reason, namely, that agents aim to be guided only by practical reasons. By way of response, it is worth noting that thinking of action as governed by this aim is consistent with various views as to the fundamental aim of action. Any such view need not be intended as opposed to the idea that subjects aim to act only on practical reasons but as providing a more revealing specification of the aim of action which would explain what it takes for a fact to provide a practical reason.

Suppose that fundamentally action aims only at the good. If one aims to $\varphi$ only if $\varphi$ ing is good, then presumably one aims to $\varphi$ only on the basis of facts which reveal $\varphi$ ing to be good in some respect, which facts, on this view, are practical reasons. Suppose that the fundamental aim of action is desire-satisfaction. If one aims to $\varphi$ only if $\varphi$ ing satisfies one's desire, then presumably one aims to $\varphi$ only on the basis of facts which reveal $\varphi$ ing to satisfy that desire, which facts, on this view, are practical reasons. Suppose that the fundamental aim of action is to have a point (cf. Millar 2004). If one aims to $\varphi$ only if $\varphi$ ing has a point, then presumably one aims to $\varphi$ only on the basis of facts which reveal $\varphi$ ing to be pointful in some respect, which facts, on this view, are practical reasons. Suppose finally that the fundamental aim of action is knowledge of what one is doing (cf. Velleman 2000). If one aims to $\varphi$ only if in $\varphi$ ing one knows what one is doing, then presumably one aims to $\varphi$ only on the basis of facts which explain what one is doing, which facts, on this view, are practical reasons.

Clearly this survey is not exhaustive but it shows that the specification of the aim of action which I appeal to above is a 'thin' one, and so relatively uncontroversial, a specification which is consistent with various 'thicker' specifications of action's aim serving different explanatory purposes. 


\subsection{Does the account assume a controversial view of practical reasoning?}

Rather than object to the account on the grounds that it assumes a controversial view of the aim of practical reason, one might object that it assumes a controversial view of practical reasoning itself. Above, I assume that the premises of practical reasoning are provided by what a subject believes, that is, the contents of her beliefs. This claim is contentious.

Fortunately, my account does not depend on it. There is not space here to review all the alternatives but I shall consider two competing views regarding what provides the premises for practical reasoning so as to show that my explanation of why subjects take only evidential considerations to justify believing does not rest on any particular conception of practical reasoning.

Suppose that the premises of practical reasoning include, not only what is believed, but also what is desired. On this view, reasoning in support of the decision to go to a certain restaurant might include among its premises an object of desire, say, to eat sushi. Whatever is to be said for such a view, it creates no problems for my story-I claim that belief aims to provide only premises fit for practical reasoning, not that it aims to provide all such premises.

The view under consideration does, however, clash with the specification I provide of the aim of action; but this can be resolved by some harmless rewording. If subjects act on the premises of practical reasoning, and if the premises of practical reasoning include what is desired, and if what is desired is not a practical reason, then it is not true, as I claim, that subjects aim to act only on what is a practical reason. But one might claim instead that subjects aim to act on what is believed only if what is believed is a practical reason, which leaves it open whether subjects act or aim to act on any other basis. Whatever is to be said in support of the original claim carries over to this revised version.

Suppose next that a premise of practical reasoning is not what is believed but the believing itself, that is, the mental state or psychological attitude rather than its content. This 
view is in no tension with the account I develop here. If a premise in practical reasoning is the state of belief, it nonetheless supports a practical conclusion only in virtue of its content, that is, only in virtue of what is believed. Thus, if the case I sketched above supports the idea that subjects aim to believe only what is a practical reason - and so only what is true - it does so whether one thinks of that which supports a practical conclusion-that is, a premise of practical reasoning — as the believing or the believed.

The view under consideration does, however, clash with the specification I provide of the aim of action, which again can be resolved by some harmless rewording. If what a subject acts or decides on the basis of are the premises of her practical reasoning, and if the premises of practical reasoning are states or attitudes of belief, then it is not true, as I claim, that subjects aim to act only on the basis of practical reasons, since states or attitudes of belief are not practical reasons, that is, facts which justify or favour actions or decisions. To put the same point differently, on the view under consideration, practical reasons are distinct from motivating reasons.

In light of this, talk of the aim to act only on what is a practical reason might be reformulated as talk of the aim to act on a state or attitude of belief only if its content is or corresponds to a practical reason. Suppose that the reason for which Hayley goes to the cinema is not the fact that the new Wenders film is showing but her believing that it is. If the new Wenders film is showing, then the content of Hayley's belief corresponds to a practical reason. Hence, in going to the cinema, Hayley satisfies the aim to act only on a basis which corresponds to a practical reason.

So, whether the premises of practical reason include desires as well as beliefs, and whether those premises are the contents of such states or the states themselves, are matters which do not matter to the explanation I give of the commitment to evidentialism. 


\subsection{What about beliefs which play no role in practical reasoning?}

I claim that the aim to act only on what is a practical reason generates or incorporates the aim to believe only what is a practical reason. One might object that a subject could accord with the former while failing to satisfy the latter, so long as the relevant belief is not one she will act on.

Perhaps, then, I have accounted for the fact that a subject cannot take practical considerations to justify or favour having a certain belief on the basis of which she will act or decide, since to do so might be to thwart her aim to act only on practical reasons. But suppose that a subject knows that, if she were to believe some utterly trivial proposition which will never figure in her practical reasoning, she would receive a large reward. Since the relevant belief is not one she would act or decide on the basis of, forming it could not conflict with her aim to act only on the basis of practical reasons. Why, then, can't she take the fact of the reward to justify believing?

First, I suggest we bring theoretical reasoning back into view. Thus, the aim of belief is to provide reasons for acting and believing, or premises on the basis of which one might do so. If the relevant subject is to take the practical consideration to justify believing the trivial proposition, she must take the belief to be, not only one which she will not act on, but one which she will not reason in any way from. It is not clear what kind of belief would pass this test.

Second, though it is legitimate to talk of believing $a$ proposition, such talk is liable to mislead. It is widely acknowledged that having one belief involves having an indefinite number of other beliefs. To return to an earlier example, to believe that David Cameron's doctor's uncle has 132,487 hairs on his head one must have numerous related beliefs about hair, familial relations, numbers, the medical profession, and so on, and for each such belief one must have numerous related beliefs. This point should make us much less confident in 
the idea of a trivial, in the sense of having no practical import, belief. While a given belief, when specified in a certain way, might seem like one a subject will not act upon, that belief stands in systematic relations to a host of other beliefs, and so acquiring or losing any such belief will have, in ways which are hard to anticipate or specify in advance, ramifications for one's overall 'web' of beliefs, on the basis of which one acts. To put the same thought differently, though it is legitimate to talk of a subject's acting on $a$ belief, what a subject really acts on is an indefinitely large set of interconnected beliefs and so, insofar as any given belief belongs to that set, it is to some extent practically significant. Once one acknowledges holism about belief, it is far less clear that one might have $a$ belief which has no consequences for the theoretical and practical conclusions one might draw.

Third, recall that the explanandum is the fact that subjects take only evidential considerations to provide reason for belief. So, the case which causes problems for my account would be one in which a subject has a certain attitude which she takes to play no role in guiding her action or thought, to be inferentially isolated from any other beliefs on the basis of which she might act, to play no part in her cognitive and practical life. Viewed in this manner, the attitude does not really look like one of belief, properly so-called. Thus, the case which my appeal to the aim of belief, and in turn the aim of action, supposedly cannot account for is not genuine. I can grant that a subject might take practical considerations to provide reason for an attitude of the sort described above, since that is not to grant that she might take such considerations to provide reason for belief.

A final and rather different response to the objection is to stress that the aim to act only on practical reasons is here presented as one which constitutively governs action in general. This, I propose, generates or incorporates an aim, namely, to believe only what is a practical reason or true, which constitutively governs belief in general. This aim is not supposed to be one which a subject, as it were, switches on and off, adopts or drops, 
according to the proposition in question. So, even if she takes a particular belief to be of no practical significance in the sense outlined above, she has a certain overarching motivational structure or make-up, given which she will take there not to be practical reasons for having that belief. Thus, the account is secure so long as it makes sense to think that a subject who aims generally to act only on the basis of practical reasons would, as a result, aim generally to believe only what is a practical reason or true, which requires that a belief which a subject knows is of no potential practical or theoretical significance whatsoever is the exception not the rule.

\subsection{Might someone have all the relevant aims and still take there to be non-evidential reasons for believing?}

To explain why subjects do not take there to be practical reasons for believing, I have appealed to the idea that subjects aim to believe only the truth, an aim dictated by the aim to believe only what is a practical reason, an aim dictated in turn by the aim to act only on the basis of practical reasons. One might object to this by appeal to an example of the following sort.

Penny has all the aims with respect to belief and action outlined above. An evil demon tells Penny that, unless she believes the next thing Chicken Little says, he will ensure that she believes lots of falsehoods. The next thing Chicken Little says (falsely and against the evidence) is that the sky is falling. Given her aim to believe only the truth, Penny would presumably take there to be a non-evidential reason to believe that the sky is falling, namely, that in so believing she will avoid believing lots of (other) falsehoods. ${ }^{16}$ This example suggests I have failed to explain why subjects cannot take there to be non-evidential reasons for believing.

\footnotetext{
${ }^{16}$ Firth (1981), in a different context, introduces cases where believing a falsehood is a means to believing many truths or avoiding other falsehoods.
} 
Note that, if there is a problem here, it is a problem for all accounts which try to derive a commitment to evidentialism from something like an aim to believe only the truth, whether that aim is presented as fundamental, as is typical, or as derivative, as in this paper.

To avoid the problem, one needs simply to be careful in how one specifies the relevant aim. The aim which I claim governs belief is not the aim to have as few false beliefs as possible; it is the aim, if a proposition is false, not to believe it (full stop). The fact that, by believing the next thing Chicken Little says, Penny will avoid believing lots of falsehoods in no way indicates that, were she so to believe, she would satisfy that aim. Indeed, believing the next Chicken Little says requires believing what is false, and so thwarts her aim to believe only what is true.

Compare the difference between the aim to minimise killing and the aim not to kill. If a subject aims to minimise killing, she might take the fact that, by killing this person, she will avoid killing those other people to be a reason for killing this person. But if a subject aims not to kill, full stop, she would not take the fact that, by killing this person, she will avoid killing those other people to be a reason for killing this person.

So, the objection is unsuccessful. If Penny aims to believe a proposition only if it is true- because she aims to act only on practical reasons - then she will not take there to be non-evidential reasons for believing that the sky is falling. ${ }^{17}$

Of course, Penny would no doubt recognise that, if she does not believe what Chicken Little says, this will in due course thwart her aim, with respect to other falsehoods, not to believe them. But this is simply to recognise an unfortunate fact about her situation, not to recognise a non-evidential reason for believing

\section{Conclusion}

\footnotetext{
${ }^{17}$ Penny might take there to be non-evidential reasons to bring it about that she believes the next thing which Chicken Little says.
} 
Subjects take only evidential, as opposed to practical, considerations to provide reason for believing because subjects aim to believe only the truth because subjects aim to believe only what is a practical reason because subjects aim in action and decision to be guided only by practical reasons. The epistemic perspective is not in tension with the practical perspective but dictated by and contained within it. In this respect, one can agree with James, that notorious critic of evidentialism, that 'our non-intellectual nature does influence our convictions' (1956: 11). Practical reason itself, in demanding that what one believes be something which could favour or justify a practical conclusion, demands that there cannot be practical reasons for belief.

At least, that is the picture I have sketched in this paper. There are, no doubt, many more details to fill in and it has not been shown that all aspects of the picture are accurate. But it seems to me that it presents our commitment to evidentialism from a potentially illuminating angle, and so is worth closer attention. Moreover, should the claim that the aim of belief is a consequence of the aim of action in the end fail to explain why subjects take there to be only evidential reasons for believing, that claim offers what remains, I think, an independently interesting picture of how one's point of view qua believer relates to one's point of view qua agent, one which might help us, in Kant's words, 'to attain insight into the unity of the whole rational faculty (theoretical as well as practical) and to derive everything from one principle' (1996: 5.91).

\section{References}

Adler, J. 2002: Belief's Own Ethics. Cambridge, Massachusetts: MIT Press

Bird, A. 2007: Justified Judging. Philosophy and Phenomenological Research 74: 81-110.

Boyle, M. 2011: Active Belief. Belief and Agency, ed. D. Hunter. Calgary: University of Calgary Press. 
Dancy, J. 2000: Practical Reality. Oxford: Oxford University Press.

Feldman, R. 2000: The Ethics of Belief. Philosophy and Phenomenological Research 60: 667-695.

Firth, R. 1981: Epistemic Merit, Intrinsic and Instrumental. Proceedings and Addresses of the American Philosophical Association 55: 5-23.

James, W. 1956: The Will to Believe and Other Essays. New York: Dover.

Kant, I. 1996: Practical Philosophy, ed. M. J. Gregor. Cambridge: Cambridge University Press.

Kelly, T. 2003: Epistemic Rationality as Instrumental Rationality: A Critique. Philosophy and Phenomenological Research 66: 612-640.

Littlejohn, C. 2012: Justification and the Truth-Connection. Cambridge: Cambridge University Press.

McHugh, C. 2011: What Do We Aim At When We Believe? dialectica 65: 369-392.

—. 2012: Belief and Aims. Philosophical Studies 160: 425-439.

—. Forthcoming: Normativism and Doxastic Deliberation. Analytic Philosophy.

Millar, A. 2004: Understanding People. Oxford: Oxford University Press.

Owens, D. 2003: Does Belief have an Aim? Philosophical Studies 115: 283-305.

Railton, P. 1994: Truth, Reason, and the Regulation of Belief. Philosophical Issues 5: 71-93.

Shah, N. 2003: How Truth Governs Belief. Philosophical Review 112: 447-482.

—. 2006: A New Argument for Evidentialism. Philosophical Quarterly 56: 481-498.

Smith, M. 1994: The Moral Problem. Oxford: Blackwell.

Steglich-Petersen, A. 2008: Does Doxastic Transparency Support Evidentialism? dialectica 62: $541-547$.

—. 2009: Weighing the Aim of Belief. Philosophical Studies 145: 395-405. 
Sullivan-Bissett, E. and Noordhof, P. 2013: A Defence of Owens' Exclusivity Objection to Beliefs Having Aims. Philosophical Studies 163: 453-457.

Velleman, J. 2000: The Possibility of Practical Reasoning. Oxford: Oxford University Press.

Whiting, D. 2010: Should I Believe the Truth? dialectica 64: 213-224.

—. 2012: Does Belief Aim (Only) at the Truth? Pacific Philosophical Quarterly.

—. 2013: Stick to the Facts: On the Norms of Assertion. Erkenntnis 78: 847-867.

—. Forthcoming: Nothing but the Truth: On the Aims and Norms of Belief. The Aim of Belief, ed. T. Chan. Oxford: Oxford University Press.

Williams, B. 1973: Problems of the Self. Cambridge: Cambridge University Press.

Williamson, T. 2000: Knowledge and its Limits. Oxford: Oxford University Press. 